\title{
ЗАРУБЕЖНЫЙ ОПЫТ ИНВЕСТИРОВАНИЯ ПЕНСИОННЫХ СРЕДСТВ В ДОЛГОСРОЧНЫЕ ИНФРАСТРУКТУРНЫЕ ПРОЕКТЫ
}

\section{FOREIGN EXPERIENCE IN INVESTING \\ PENSION FUNDS IN LONG-TERM \\ INFRASTRUCTURE PROJECTS}

\section{T. Esaulkova}

Summary. The problem of investing pension funds in infrastructure projects exists not only in Russia but throughout the world. To date, the rich experience of foreign countries has already been accumulated in this regard, which requires generalization and analysis. In the article highlights the main current models for the participation of pension funds in infrastructure projects: direct investment; through various investment funds; collective financing with other institutional investor. The objectives of investing pension funds in long-term infrastructure projects for funds are variable: the need to diversify the investment portfolio, ensuring a stable income (as a rule, due to a predetermined rate of return), ongterm nature of liabilities (which corresponds to the maturity of pension obligations), ensuring an acceptable level of risk due to low volatility. At the same time, there are risks associated with the low quality of infrastructure projects, limited availability of high quality assets, come from which exceeds the risk-free rate of return, high costs of acquiring these assets, etc.).

Keywords: investment, pension assets, infrastructure projects, pension funds, investment portfolio, risks.
$\mathbf{T}$ радиционно пенсионные фонды инвестировали/ размещали пенсионные средства в акции и облигации, но постепенно их инвестиционные портфели стали занимать так называемые «альтернативные инвестиции», куда вошли прямые инвестиции, инвестиции в инфраструктуру, недвижимость. Суммарно за последние 20 лет доля этих активов в инвестиционном портфеле пенсионных фондов, по мнению Аналитического центра «Thinking Ahead Institute», изучившего данные процессы в 22-х экономически развитых странах мира, «возросла с 4\% до более чем 20\%» $[11$; 3, с. 5], что свидетельствует об устойчивом интересе участников пенсионного рынка к долгосрочному инвестированию. В отдельных странах (например, в Австралии, Канаде и пр.) доля вложений пенсионных фондов в инфраструктурные проекты может быть на уровне 10-15\%. К этому следует добавить еще вложения в муниципальные облигации, связанные с вложениями в инфраструктуру - около 15\%, что в совокупности составляет 25-30\%.
Есаулкова Татьяна Станиславовна

К.э.н., Всероссийский научно-исследовательский институт труда при Минтруде России (Москва)

sovet@vcot.info

Аннотация. Проблема инвестирования пенсионных средств в инфраструктурные проекты существует не только в России, но и во всем мире. К настоящему времени в этом отношении уже накоплен богатый опыт зарубежных стран, который требует обобщения и анализа. В статье выделены основные существующие в настоящее время модели участия пенсионных фондов в инфраструктурных проектах: прямое инвестирование; через различные инвестиционные фонды; коллективное финансирование с другими институциональными инвесторами. Цели инвестирования пенсионных средств в долгосрочные инфраструктурные проекты для фондов вариативны: необходимость диверсификации инвестиционного портфеля, обеспечение стабильного дохода (как правило, ввиду заранее определенной нормы доходности), долгосрочный характер обязательств (что соответствует срокам исполнения пенсионных обязательств), обеспечение приемлемого уровня риска в виду низкой волатильности. Одновременно имеют место и риски, связанные с низким качеством инфраструктурных проектов, ограниченностью наличия высококачественных активов, доход от которых превышает безрисковую ставку доходности, высокие затраты на приобретение данных активов и пр.).

Ключевые слова: инвестирование, пенсионные активы, инфраструктурные проекты, пенсионные фонды, инвестиционный портфель, риски.

Согласно рейтингу крупнейших мировых инвесторов, опубликованному «Investment \& Pensions Europe» осенью 2019 года [9], среди лидеров названы: Управляющая активами канадского пенсионного фонда корпорация «Canada Pension Plan Investment Board» (2 место в рейтинге: совокупные активы \$293,5 млрд., из них \$24,9 млрд. вложены в инфраструктурные проекты); Государственный пенсионный фонд Южной Kореи «National Pension Service» (3 место в рейтинге: \$575,2 млрд.- совокупные активы, из них $\$ 20,5$ млрд. вложены в инфраструктурные проекты). По расчетам экспертов МВФ и как показывает опыт 120 стран, увеличение объема инвестиций в инфраструктурные проекты на 1\% от ВВП приводит к росту последнего на 1,5\% [5].

Цели инвестирования в долгосрочные инфраструктурные проекты вариативны: необходимость диверсификации инвестиционного портфеля, обеспечение стабильного дохода (как правило, ввиду заранее опре- 
деленной нормы доходности), долгосрочный характер обязательств (что соответствует срокам исполнения пенсионных обязательств), обеспечение приемлемого уровня риска в виду низкой волатильности и пр.

Среди основных отраслевых направлений инфраструктурных вложений зарубежных пенсионных фондов: транспорт, энергетика (в том числе возобновляемая энергия), трансфер, телекоммуникации, водоснабжение, дорожное строительство, коммерческая недвижимость, социальная инфраструктура и пр. Объем инвестиций пенсионных фондов в различные сектора в разных странах существенно различается.

Эксперты нередко разделяют инфраструктурные инвестиции не по отраслевой структуре, а способам возвратности инвестиций (например, с одной стороны, выделяют социальное инвестирование с низкой доходностью и одновременно с низким уровнем риска, так как данное инвестирование нередко поддерживается государством, а, с другой стороны, инвестирование в коммерческие объекты - с высокой доходностью, но и высоким уровнем риска). В связи с развитием концепции социально ответственного инвестирования большую роль начинают играть так называемые «зеленые облигации» в инвестировании пенсионных активов (в том числе через «зеленые» инфраструктурные фонды).

Анализ зарубежного опыта позволяет выделить разные модели участия пенсионных фондов в финансировании инфраструктурных проектов, среди них:

- самостоятельные поиск инфраструктурных проектов и их финансирование (прямое инвестирование);

- участие в финансировании через различные инвестиционные фонды (например, инфраструктурные фонды и инвестиционные платформы);

- коллективное финансирование с другими институциональными инвесторами (в связи с этим в последние годы сформировалось понятие «инвестиционный управляющий» /«infrastructure assets managers»/) [7].

Инвестиции в инфраструктуру можно классифицировать и на основе типологии используемых финансовых инструментов [10], в связи с этим выделяют:

- долевые и долговые инвестиции (описывает тип экономического воздействия на инфраструктурные активы);

- прямое воздействие (инвестиции в проектный капитал и инфраструктурные фонды, инвестирующие в собственный капитал проекта) и долговые обязательства (например, облигации проекта или кредиты);
- косвенные инвестиции, например, через котируемые корпоративные акции или корпоративные облигации, а также такие инструменты, как взаимные инвестиционные фонды и трастовые фонды, которые инвестируют в акции инфраструктурных корпораций или в проекты.

Прямое самостоятельное инвестирование в объекты инфраструктуры, как правило, реализуют лишь крупнейшие пенсионные фонды (такие инвестиции не превышают 1\% суммарных активов [6]). Бо́льшая часть пенсионных фондов применяют косвенные инвестиции.

Одной из распространенных форм инвестирования пенсионных фондов в инфраструктурные проекты является использование инвестиционных фондов. Пенсионные фонды могут быть сами учредителями данных фондов (например, один из таких инвестиционных фондов в Великобритании был создан «Партнерством муниципальных пенсионных фондов Великобритании LGPS Central» [4, c. 5]). Вместе с тем можно выделить ряд пенсионных фондов, которые совершают самостоятельные инвестиции в инфраструктуру (например, «Пенсионный фонд учителей Калифорнии /CaISTRS/», «Пенсионный фонд государственных служащих Калифорнии / CalPERS/» [4, с. 5]) и др.). Нередко сделки по вложениям пенсионных средств в инфраструктуру совершаются через «проектные компании» (special-purpose vehicle, SPV), «которые позволяют управлять отдельными бизнес-процессами или финансовыми потоками» [4, с. 5]. Среди иных форм: инвестирование через инфраструктурные компании (Бразилия, Перу, Китай), фонды частных акций (Бразилия, Колумбия, Южная Африка); покупка инфраструктурных облигаций (Чили, Колумбия, Перу, Южная Африка). В США на уровне отдельных штатов присутствуют все формы инвестирования пенсионных средств в инфраструктурные проекты, которые реализуются через механизмы частно-государственного и государственно-частного партнерств, разнообразные фонды (например, водоснабжения, электроэнергетики) и пр.

Следует отметить и появление как результата государственно-частного партнерства нового класса активов в сфере инфраструктурных инвестиций, а именно нелистинговых неликвидных инфраструктурных активов, которые существуют наряду с листинговыми инфраструктурными активами (акции, облигации), но не обращаются на бирже. К таким активам относятся: недвижимость, объекты инфраструктуры и частные инвестиции. Данные активы привлекательны для инвесторов не только своей возможной стабильной (например, через договоры аренды, тарифные соглашения), но и повышенной доходностью (при условии эффективного управления рисками), а также ее долгосрочностью. 
Таблица 1. Распределение инвестиций в инфраструктуру в общей структуре инвестиционного портфеля пенсионных фондов на примере ряда стран ОЭСР в 2017 году, в \%

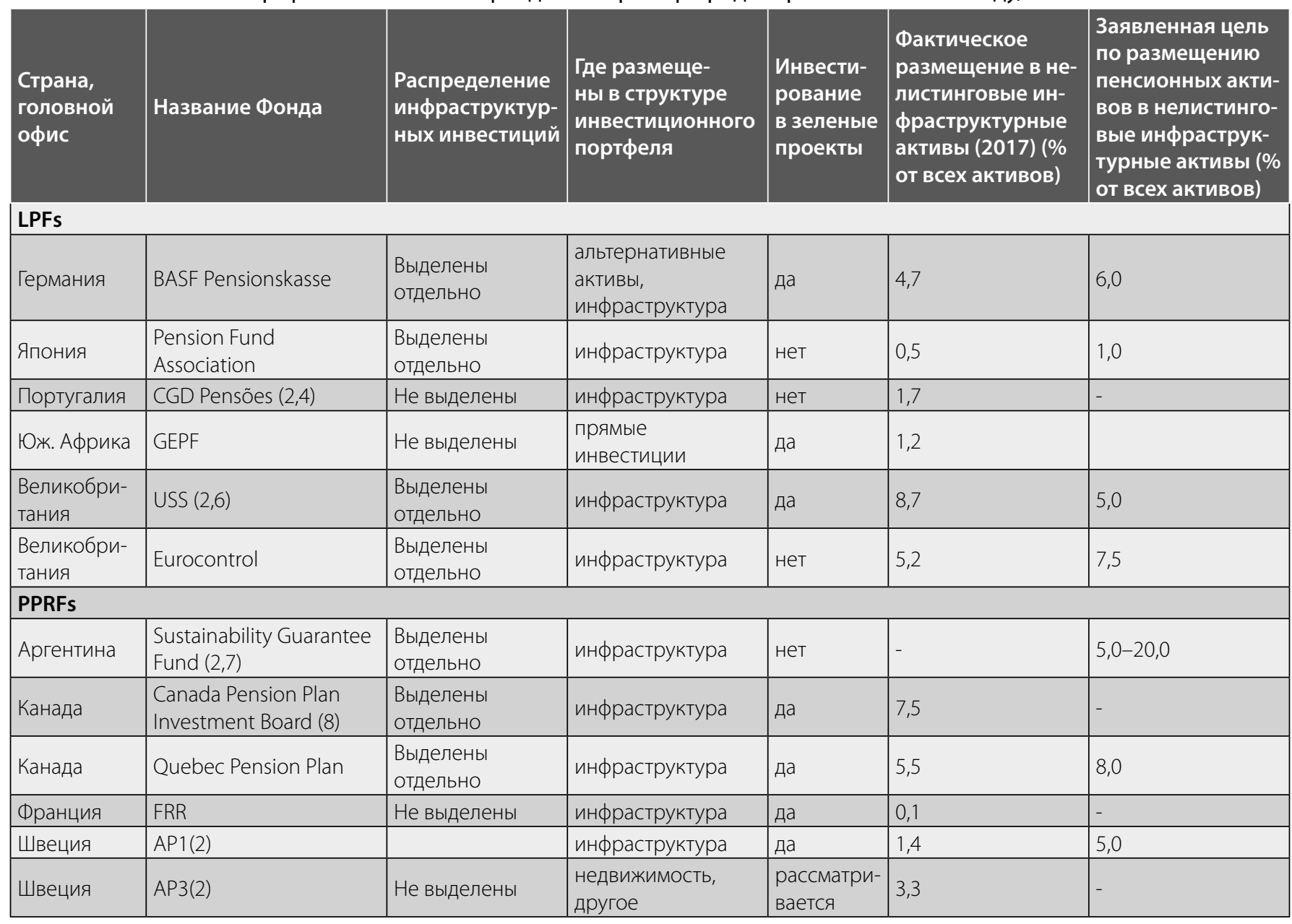

Источник: расчеты ОЭСР, основанные на ответах, сформулированных в ходе обследования, проведенного в рамках ОЭСР [10].

Среди новых объектов инвестирования выделим и проектные облигации, введенные по совместной инициативе Европейского инвестиционного банка (ЕИБ) и Европейской комиссии (ЕК) [2, с. 7]. Данные облигации могут быть как листинговыми, так и нелистинговыми, использоваться для финансирования, как коммерческих проектов, так и проектов в рамках государственно-частного партнерства. Они выпускаются проектными компаниями и погашаются за счет их финансовых средств.

В таблице 1 представлено распределение инфраструктурных инвестиций в общей структуре инвестиционного портфеля пенсионных фондов (крупных пенсионных фондов - LPFs и государственных пенсионных резервных фондов - PPRFs) на примере ряда стран ОЭСР в 2017 году [10].

Еще в 2016 году инвестиции в инфраструктуру в ряде стран ОЭСР были выделены в отдельный класс активов - реальные активы («real assets»). Реальные активы - это вложения в инфраструктуру, недвижимость, альтернативные инвестиции (активы), прямые инвестиции, инвестиции в развитие. Что касается понятия «инфраструктурные облигации», то, как правило, этим термином обозначаются облигации, выпущенные для финансирования того или иного объекта инфраструктуры ${ }^{1}$.

Потенциал увеличения объема инфраструктурных инвестиций достаточно большой (в 2017 году совокупный объем таких активов по 99 LPFs и PPRFs составил сумму \$9 трлн. [10]). Фонды инвестируют как в нелистинговые инфраструктурные активы (не включенные в листинг до-

В законодательстве ряда стран есть свои нюансы: например, в ряде штатов США этот термин обозначает облигации для финансирования строительства объекта инфраструктуры, причем строительство рассматривается и как реконструкция, и как возведение нового объекта; однако в некоторых случаях употребляется иной термин «revenue bonds», означающий облигации, приносящие доходы, обеспеченные поступлениями [1]. 
левые инструменты), в частности, через прямые инвестиции, или инфраструктурные фонды, так и в выделенные целевые ассигнования для этой категории активов. Доля инфраструктурных инвестиций может составлять 1010,1\% в структуре инвестиционного портфеля фонда (как, например, в Австралии - Hostplus Superannuation fund; в Канаде - OTPP(1), a Canada Local Authorities Pension Plan намерен увеличить эту долю до 15\%). Существует и потенциал фондов в расширении институциональных инвестиций в инфраструктуру. Целевые ассигнования на инфраструктуру колебались на низком уровне от 1\% до $20 \%$ от общего объема активов (данные за 2017 год [10]).

Среди причин, по которым пенсионные фонды не инвестируют в большом объеме пенсионные активы в инфраструктуру,- ограничения со стороны госрегулятора (например, инвестиции в нелистинговые активы в Бразилии могут составлять не более 20\%; в Южной Африке - разрешено инвестировать 5\% в акции, не имеющие листинга, хотя интерес самих фондов к подобному инвестированию существует; однако ограничения есть не везде, в частности, в Канаде такие ограничения отсутствуют вовсе). Во многих странах разрешено инвестирование пенсионных средств только на листинговых рынках. Вместе с тем глобальные потребности в новых инфраструктурных активах достаточно велики (по оценкам ОЭСР, «С 2015 по 2030 год глобальные потребности в новых инфраструктурных активах составляют $\$ 90$ трлн., что больше, чем стоимость существующего фонда инфраструктуры во всем мире» [8]).

Отмечая расширение объема инвестиций пенсионных активов в инфраструктурные проекты, а также связанные с этим возможности для широкой диверсификации инвестиционного портфеля фондов, относительную стабильность и предсказуемость доходности таких вложений, одновременно следует указать и на их риски (например, риски, связанные с низким качеством инфраструктурных проектов, ограниченность наличия высококачественных активов, доход от которых превышает безрисковую ставку доходности; высокие затраты на приобретение данных активов и пр.). Одновременно, по данным опроса, проведенного в июле 2019 года информационно-аналитической службой Preqin, большинство инвесторов в целом удовлетворены вложениями в долгосрочные инфраструктурные проекты (так, 70\% респондентов отметили, что такие инвестиции отвечали их ожиданиям, для 14\% респондентов - превзошли ожидания и лишь 16\% респондентов не были удовлетворены подобными инвестициями $[4$, с. 23]).

\section{ЛИТЕРАТУРА}

1. Абдулкадыров С. С. Понятие, содержание и сущность проектных облигаций в России и за рубежом //Международное публичное и частное право.2014. 一 № 4. - C. 23-26.

2. Аналитическая записка «0 состоянии и направлениях развития рынка долгосрочных инвестиций в инфраструктуру России» Экспертного совета по рынку долгосрочных инвестиций при Банке России.- М., 2018.

3. НАКДИ. Ежеквартальный информационно-аналитический бюллетень «Институциональные инвестиции в инфраструктурные активы. Пенсионные фонды и управляющие компании».— 2019.— № 1(16), 1-й квартал.

4. НАКДИ. Ежеквартальный информационно-аналитический бюллетень «Институциональные инвестиции в инфраструктурные активы. Пенсионные фонды и управляющие компании».— 2019. — № 3(18), 3-й квартал.

5. НАКДИ. Investinfra [Электронный ресурс]. Режим доступа: https://investinfra.ru/novosti/pensionnye-resursy-stanut-vazhnym-istochnikom-dolgosrochnyhinvesticiy.html.— (дата обращения: 05.05.2020).

6. НАПФ. Предложения по механизмам инвестирования средств НПФ в инфраструктурные проекты [Электронный ресурс]. Режим доступа: парf. rusfiles/71536/pf_infr_inv_doc._- (дата обращения: 05.05.2020).

7. Национальное рейтинговое агентство. Привлечение активов пенсионных фондов в инфраструктурные проекты: Модели участия и барьеры инвестирования [Электронный ресурс]. Режим доступа: investinfra.ru/frontend/images/PDF/Виктор\%20Четверяков\%2C\%20«Привлечение\%20активов\%20пенсионных\% 20фондов\%20в\%20инфраструктурные\%20проекты\%20Модели\%20участия\%20и\%20барьеры\%20инвестирования».рdf — (дата 0бращения: 05.05.2020).

8. Пенсионные инвестиции: глобальные вызовы и мегатренды [Электронный ресурс]. Режим доступа: https://gavrilenko.ag/wp-content/uploads/2018/01/ koncessii-block-Final_Part2.pdf._- (дата обращения: 05.05.2020).

9. IPE, TOP-100 Infrastructure Investors 2019.

10. OECD (2019), Annual Survey of Large Pension Funds and Public Pension Reserve Funds [Электронный ресурс]. Режим доступа: www.oecd.org/finance/surveylarge-pension-funds.htm. - (дата обращения: 05.05.2020).

11. The Global Pension Assets Study 2019 https://www.thinkingaheadinstitute.org/en/Library/Public/Research-and-Ideas/2019/02/Global-Pension-AssetSurvey-2019. - (дата обращения: 05.05.2020).

(c) Есаулкова Татьяна Станиславовна ( sovet@vcot.info ).

Журнал «Современная наука: актуальные проблемы теории и практики» 